\title{
Development and Design of a Centrifugal Compressor Volute
}

\author{
Cheng Xu \\ Ingersoll-Rand, Davidson, NC 28036, USA \\ Email: cheng_xu@ingersoll-rand.com \\ Michael Müller \\ Ingersoll-Rand, Davidson, NC 28036, USA \\ Email: michael.muller@ingersoll-rand.com
}

Received 25 April 2005

\begin{abstract}
The volute is one of the key components of a centrifugal compressor. The design of the volute not only impacts the compressor efficiency but also influences the operating range. The detailed flow simulation presented here helps to better understand the volute flow mechanisms and provide design guidance in volute design to meet performance goals. In this study, the viscous Navier-Stokes equations are used to simulate the flow inside the vaneless diffuser and volute. The detailed flow structures for different volute tongue geometries are studied in detail. The numerical calculations are compared with experimental data and good agreement is found. The results also suggest direction for further investigations in volute design.
\end{abstract}

Keywords and phrases: centrifugal compressor, volute, tongue structure.

\section{INTRODUCTION}

With the development of aviation and industry, compression technology has made large progress in both axial and radial compressors. Centrifugal compressors can make use of the radius change across the impeller. This allows for more diffusion within the impeller blade; thus a centrifugal stage can produce much higher specific work transfer than an axial stage. At high flow, the efficiency of a centrifugal compressor is not as high as that of an axial compressor. However, centrifugal compressors have wide application for aviation and industry, and are preferred for handling small volumetric flows. The physical length is shorter and the operating range is wider as compared to an axial compressor.

Increased efficiency has been the traditional emphasis of compressor design. However, increased operating range has become important in an age of ever-increasing productivity and energy costs; a "multitasking" compressor has economic benefits.

Centrifugal compressors consist of three main parts, as shown in Figure 1. The first is a rotating impeller, which imparts work to the gas by increasing its angular momentum.

This is an open access article distributed under the Creative Commons Attribution License, which permits unrestricted use, distribution, and reproduction in any medium, provided the original work is properly cited.
The fluid static pressure and absolute velocity (stationary frame of reference) increase through the impeller passage. The second component is the diffuser section, often with vanes to increase the effectiveness. The diffuser converts the kinetic energy into the static pressure by decelerating the fluid. The third and final component is a volute or collector, used for collecting the gas from diffuser and delivering to the outlet pipe.

A volute has two functions: collection and diffusion. The volute must collect and transport the fluid to the downstream system. It also raises the static pressure by converting kinetic energy $\left(\rho u^{2}\right)$ to potential energy (static pressure). The latter function has performance benefits, as the discharge pressure is increased.

The fluid leaving the impeller follows a logarithmic spiral due to the rotation of the impeller. This strong swirl of the fluid entering the volute complicates the volute design, as the flow is strongly three-dimensional. Diffusion in the volute is more effective for the kinetic energy associated with the tangential velocity; this is accomplished by increasing the crosssectional area from volute tongue to exit, creating a conical diffuser. But there is often an efficiency loss arising from the inability of the volute to convert the kinetic energy associated with the radial component of the velocity out of the diffuser. This effect is compounded when a vaned diffuser is used, as the vanes create a more radial flow into the diffuser. Typically, 


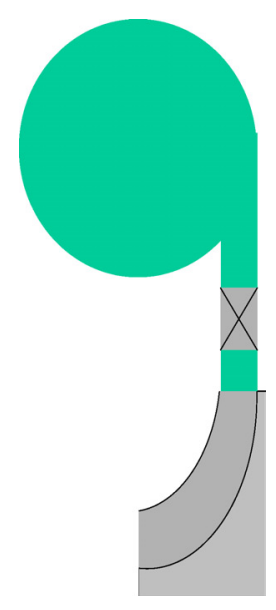

(a)

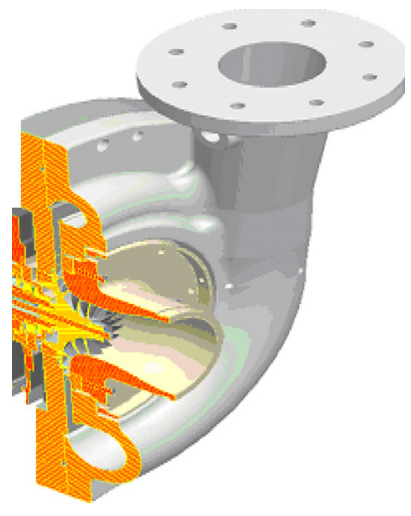

(b)
FIgURE 1: Centrifugal compressor layout. (a) A cross-sectional view, showing the impeller followed by a vaned diffuser, and a volute. (b) An isometric view of the package.

the tradeoff between increased recovery of the vaned diffuser and reduced recovery of the volute suggests using a vaned diffuser due to the performance requirements.

Little research has been done to understand the flow in volutes, especially in the tongue area (Ayder [1], Ayder and Van den Braembussche [2], Ayder et al. [3], and Gu et al. [4]). Recently, research (Ayder [1]) has found that a good volute design could improve the compressor performance and operating range. Most volute studies have been performed on existing geometries and can be categorized into two groups: volute flow analysis (Ayder [1]) and flow interactions between volute and impeller (Gu et al. [4]). Most of the studies were based on the pump. There is very limited literature to study the centrifugal compressor volute. There is little information available for the guidance of the volute design and design parameters influences of the performance.

There are five key geometrical parameters in volute design (Ayder [1]) circumferential variation of the crosssectional area; shape of the cross-section; radial position of the cross section; position of the volute inlet; and tongue geometry. A design requirement is to make the circumferential pressure distribution uniform.

The "tongue" of a volute is located at $360^{\circ}$ point of the volute, corresponding to a joint of the volute smallest area, largest area, and exit cone. At this point, the flow in the volute encounters a dividing plane, the so-called "tongue," above which the flow exits the compressor, below which the flow reenters the volute. The leading edge of the tongue is analogous to that of an airfoil, a sharp leading edge has low blockage but is sensitive to angle of attack; while a well-rounded leading edge has large blockage but is insensitive to incidence. This difference manifests itself as a design tradeoff: a sharp volute tongue provides the absolute peak efficiency, while a volute with a round tongue has better off-design performance compared.
Given the economic incentive for both efficiency and range, the focus of this paper is to gain a better understanding of the influence of the tongue. Given this knowledge, a compressor with higher efficiency and greater stable operating region can be designed.

Traditional volute design is based on two-dimensional analysis, and the emphasis is on collection and less on the diffusion function. However, with the advent of advanced fluid modeling tools, it is possible to design a volute using three-dimensional analysis. The volute design and analysis presented is indeed part of a new product in development at Ingersoll-Rand.

\section{VOLUTE DESIGN CONSIDERATIONS AND PROCESS}

The volute design objective is to meet the overall compressor efficiency and operating range goals. The cross-sectional shape is designed mainly from manufacturing and compressor packaging constraints. Volutes are typically cast, and are therefore expensive to manufacture and not practical to change. First-pass designs must achieve a high success, and to do this the fundamental flow structure must be understood along with manufacturing limitations. In this study, the velocity enters the volute at a tangential angle of about $65^{\circ}$ at design flow, thus the dominant part (> 80\%) of the total kinetic energy available is associated with velocity in the radial direction.

The volute design process in this study embraces two basic considerations. First, angular momentum and mass conservation are assumed. Second, during the first design iteration, it is assumed that the pressure and velocity are independent of the angular angle, and the tongue leakage is assumed. Based on these considerations, the volute section at a given angle can be defined. Different volute crosssection shapes are analyzed. It is found that there are only small differences that occur for all the asymmetric volute sections. For this particular case, the installation space is unrestricted, so the volute radial position is chosen by applying angular momentum conservation. The position of the volute inlet is designed tangential to the diffuser end wall as shown in Figure 1. Ease of manufacture drives this consideration.

An important design parameter is the tongue geometry. Most of the recent research (Chu et al. [5] and Dong [6]) investigates the effect of the tongue shape on head, pressure fluctuations, and noise in a centrifugal pump. Irabu et al. [7] study the water flow around the volute tongue using a partial tracking method. The research is focused on the low flow operating region. The study finds that the flow separation occurs from both upper and lower surfaces of the tongue. It is important to understand the flow structure around the tongue for improving the design.

After the basic volute shape is constructed, a threedimensional turbulence commercial software CFX-5 solver is used as to analyze the volute performance. The volute pressure recovery and internal losses are calculated with the 


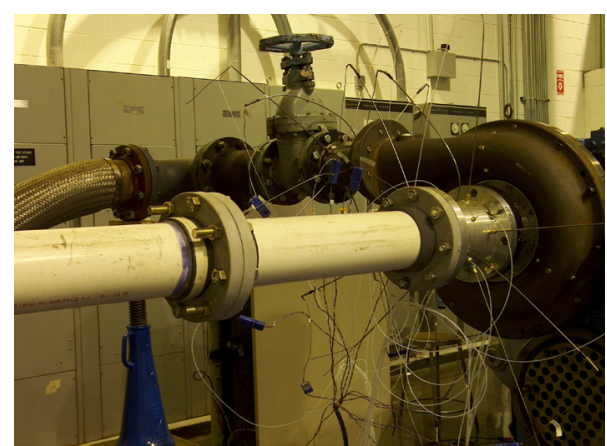

FIGURE 2: Ingersoll-Rand test rig of the single-stage compressor. The inlet pipe is the white pipe coming from the left of the image. The compressor discharges through the flex hose visible just above the inlet pipe. The regulating butterfly valve can be seen in the background.

three-dimensional analysis at design flow rate. Some final modifications are made after this initial analysis, replacing the previous assumptions with analytic values. Different tongue geometries are analyzed. From these analyses, an optimal radius is found to provide a good efficiency in a wide operating range.

\section{EXPERIMENTAL STUDY}

The final volute design was installed with its corresponding compressor and tested at the Ingersoll-Rand Development Laboratory. The test and data acquisition procedures are based on the ASME performance test procedure, ASME [8].

The test compressor consists of an inlet pipe, impeller, vaneless diffuser, vaned diffuser, vaneless diffuser, and volute. This study considers the volute preceded by a low solidity vaned diffuser as shown in Figure 1. The test circuit is an open loop testing system as shown in Figure 2. The flow rate is regulated by a butterfly valve located at the discharge pipe. The performance characteristic was tested through five total temperature and total pressure measurements at inlet and discharge of the volute exit cone. For determining the static pressure ratio, five pressure transducer taps, circumferentially distributed, were mounted on the wall at the discharge of volute exit cone. The mass flow was measured by using an ASME [8] nozzle located at the end of discharge pipe. The tip clearance of the impeller at tip was measured with graphite pins. The test uncertainty for the flow rate is less than $2 \%$ at $95 \%$ confidence level. The head and efficiency uncertainties were kept under $2.2 \%$ and $2.5 \%$, respectively, with the same confidence level based on the system uncertainty analysis (Kline [9]). The performance test results are shown in Figure 3. It is shown that the compressor developed by this research has a wide operating range up to $40 \%$ with corresponding high efficiency over a wide range.

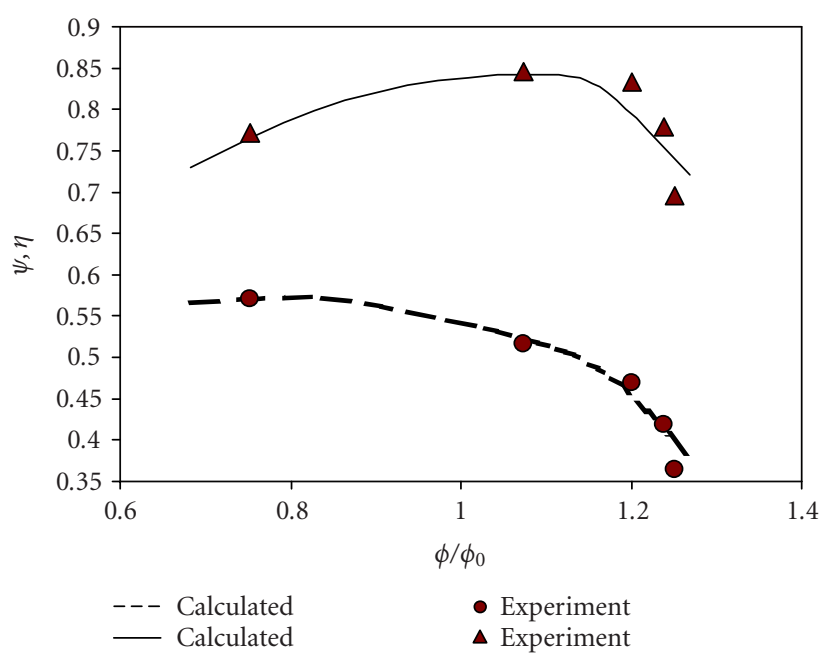

Figure 3: Calculated and measured performance characteristics, showing a good agreement between the two.

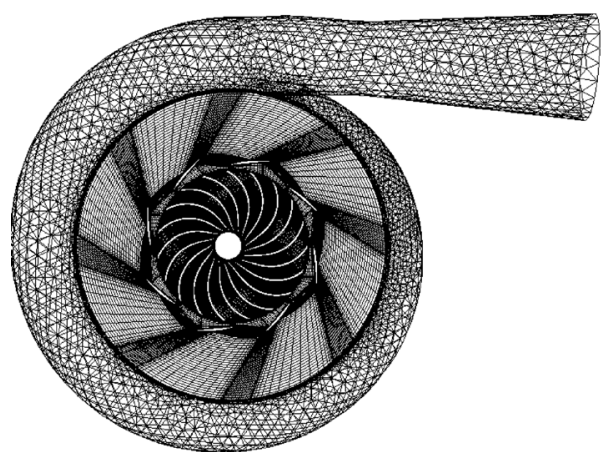

Figure 4: The computational mesh, which includes the impeller, vaned and diffuser sections, and the volute.

\section{MATHEMATICAL MODEL DESCRIPTIONS}

The volute, together with the impeller and vaned diffuser, is computationally investigated using a commercial NavierStokes solver, CFX 5.6. This code is a fully $3 \mathrm{D}$ viscous turbulent flow solver. The geometrical discretization of the compressor stage is made for the computational analysis.

Structure hexahedral cells are generated in the impeller inlet, impeller, and diffuser zones. An unstructured tetrahedral mesh with prism layers near the wall surfaces is used for the volute. The mesh is shown in Figure 4. The mesh sizes for inlet pipe, impeller, diffuser, and volute are $2.2 \times 10^{4}, 5.2 \times$ $10^{5}, 2.4 \times 10^{5}$, and $5.7 \times 10^{5}$ nodes, respectively. In the volute mesh generation, a refine zone is defined near the tongue. The frozen-rotor method is used at interfaces between rotating and stationary elements. "Frozen rotor" indicates that the relative orientation of the two interface components across the interface is fixed. The calculation of the downstream surface of the interface plan was based on the average mixing plane approach. Interfaces are located at the surface between the inlet and impeller, and between the impeller and diffuser. 


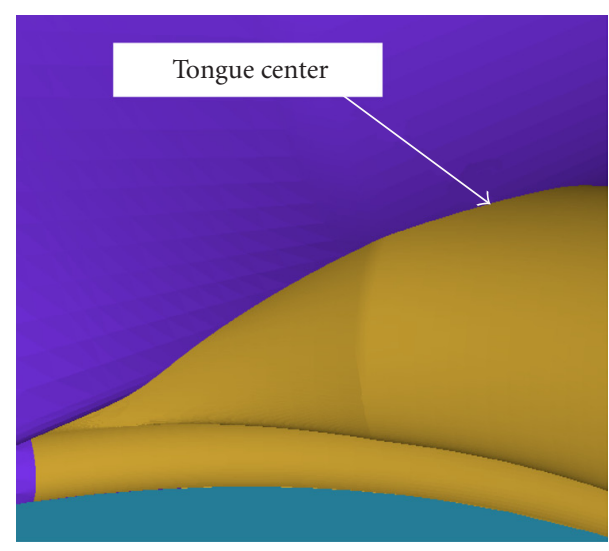

(a)

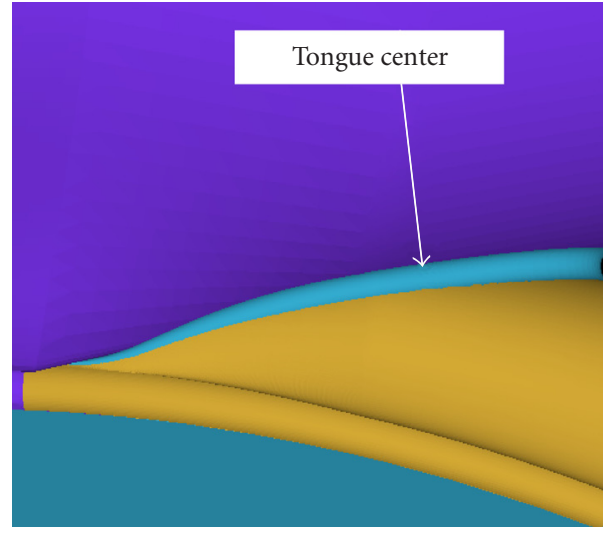

(b)

FIgURE 5: The tongue structures, showing a variation in the leading edge. (a) Sharp tongue, $r / b=0$ (knife-edge). (b) Round tongue, $r / b=0.3$.

The turbulence model used here is based on a zeroequation model; only an algebraic equation was used to calculate the viscous contribution from turbulent eddies.

The boundary conditions at the inlet are enforced by using total pressure and total temperature. The flow to the inlet pipe is assumed normal to the inlet surface. The outlet boundary condition is applied by using a variable static pressure proportional to the kinetic energy at the outlet. The flow rate of the compressor is changed by modifying the static pressure to kinetic energy ratio at the outlet condition, which simulates increasing backpressure. Zero-slip boundary conditions were imposed over the impeller blades, diffuser airfoils, and all solid walls.

The calculation was performed using an HP 8000c workstation. The time step is set to $5.0 \cdot 10^{-5}$ seconds for all calculations. The calculation is assumed to be convergent when the ratio between the sum of the residuals and the sum of the fluxes for a given variable in all of the cells is reduced to five orders of magnitude. Intensive grid-size dependence tests were carried out [10] and overall compressor performance was compared with different mesh sizes. The mesh is determined to be fine enough when with the flow rate variations less than $5 \%$ with the increased mesh density.

\section{RESULTS AND DISCUSSION}

In this study, four different types of tongues are investigated, that is, $r / b_{2}=0, r / b_{2}=0.75, r / b_{2}=0.15$, and $r / b_{2}=0.3$. Figure 5 shows two typical tongue structures considered, sharp tongue $\left(r / b_{2}=0\right)$ and round tongue $\left(r / b_{2}=0.3\right)$, showing the variation at the leading edge. It is worth to point out that all tongue locations studies here are of cutback tongues, which allow some flow recirculation. The cut back is about $9^{\circ}$ from the full tongue location. Three operating points are calculated for each tongue, while five operating points are calculated for the final designed volute. The calculated performance based on $r / b_{2}=0.3$ tongue is shown in Figure 3. It shows that the calculation results are in good agreement with experimental data. It is shown that only at the operating point near choke, calculation showed more choke margin than experimental data.

Figures 6 and 7 show the secondary flow vectors (i.e., normal to the mean flow) at sections $\theta=180^{\circ}$ and $\theta=360^{\circ}$, for both the sharp and round tongues. It can be seen that the flow in the volute sections has a single vortex structure, as opposed to two counter-rotating vortices. The round tongue creates significant blockage near the tongue. This blockage forces secondary flow center away from the tongue area. Figure 8 shows the similarity in the basic flow structure near the tongue.

Figures 9 and 10 show computational static pressure contours for the two tongue geometries. It is shown that sharp tongue has a more uniform pressure. This may be due to the impacts of the tongue blockage. Figure 11 shows the total pressure Contours for both sharp and round tongues. This figure indicates that the round tongue produces a high loss near the tongue area. The loss associated with the observed asymmetry may produce the asymmetric secondary flow profile seen in Figures 6 and 7.

Figure 12 shows the pressure coefficient as a function of the flow coefficient for the two different volute tongue geometries. This figure shows that the round tongue provides the improved pressure coefficient at high flow as compared to the sharp tongue. However, the absolute peak pressure recovery is attained with the sharp tongue, at a loss of range.

\section{CONCLUSION}

In this study, a detailed CFD analysis for different volute tongues is presented. The detailed flow structures are shown and the compressor performance is calculated for different tongues. A performance test validates the CFD analysis for the final design. It is shown that the round tongue produces better performance than the sharp tongue. It is also 


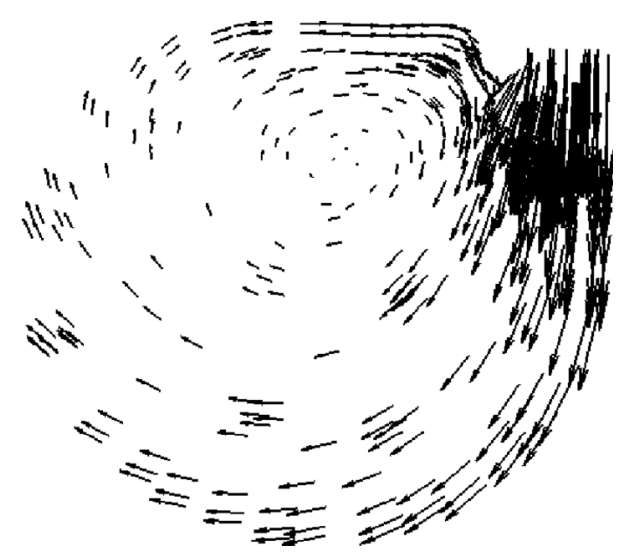

(a)

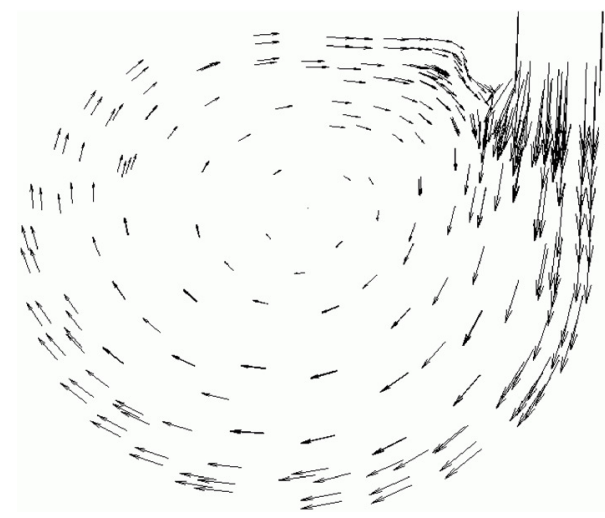

(b)

Figure 6: The velocity vectors versus the volute exit $\left(\theta=180^{\circ}\right)$. A single vortex is observed, indicating a well-sized volute. (a) Sharp tongue. (b) Round tongue, showing a shifted vortex center resulting from increased blockage near the tongue.

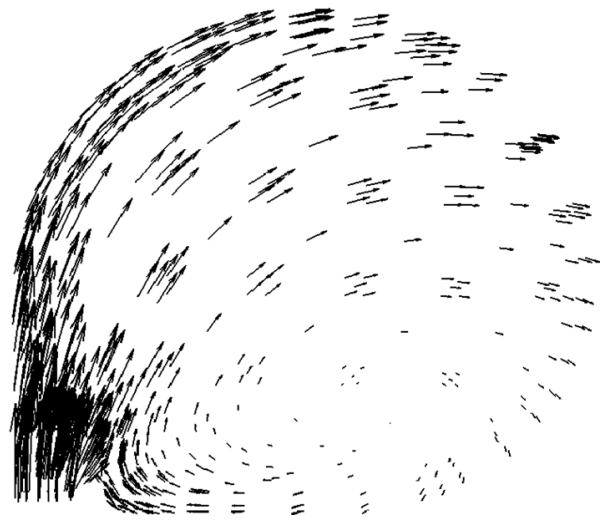

(a)

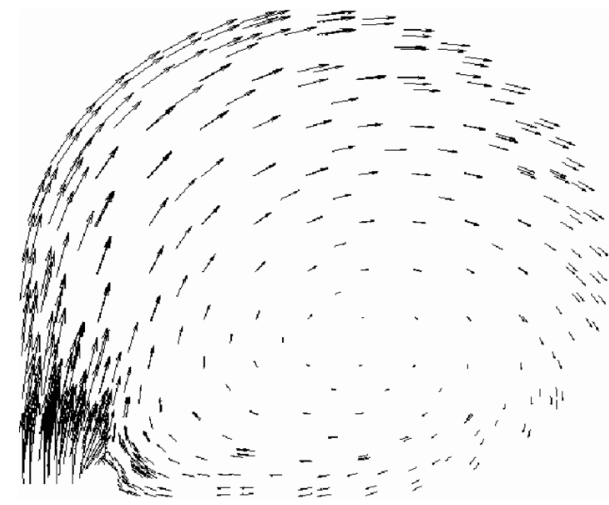

(b)

Figure 7: The velocity vectors at the volute exit $\left(\theta=360^{\circ}\right)$. Similar observations as in Figure 6 are made. (a) Sharp tongue. (b) Round tongue.

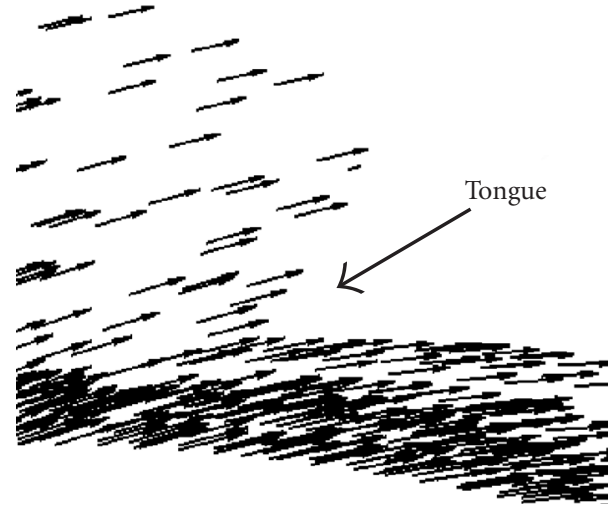

(a)

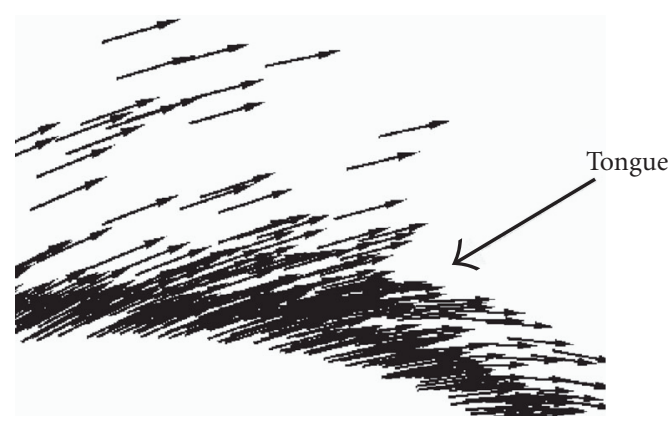

(b)

Figure 8: The velocity vectors near the intersection between the midplanes of the diffuser and tongue, showing the basic flow structure. (a) Sharp tongue. (b) Round tongue. 


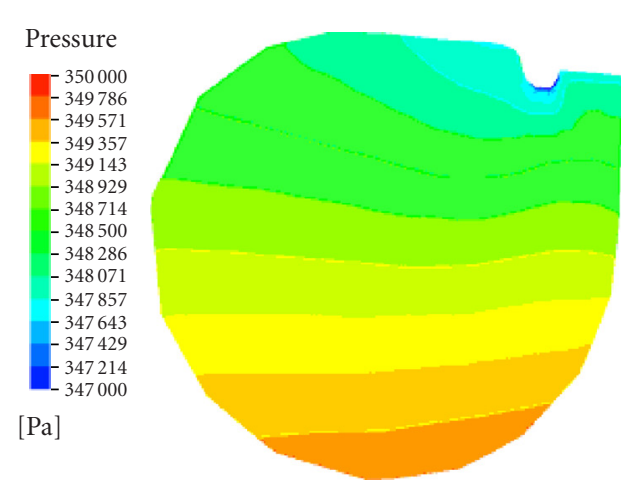

(a)

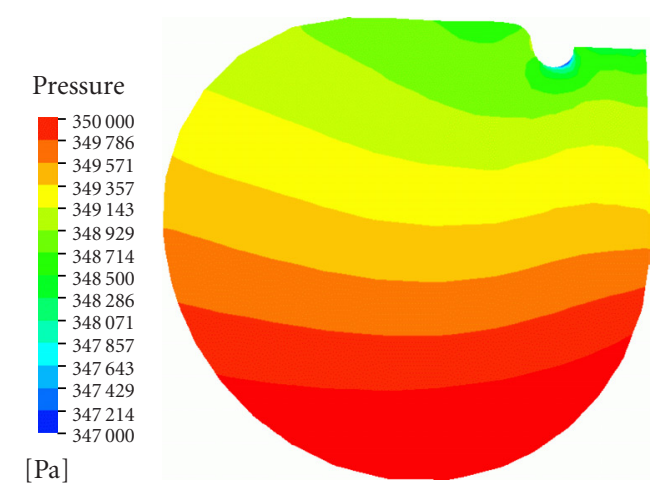

(b)

FiguRE 9: Static pressure contours versus the volute exit $\left(\theta=180^{\circ}\right)$. (a) Sharp tongue. (b) Round tongue, indicating a much less uniform pressure distribution.

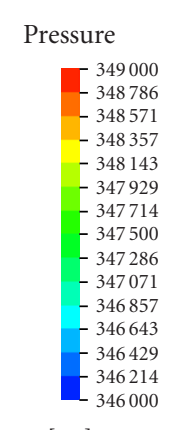

$[\mathrm{Pa}]$

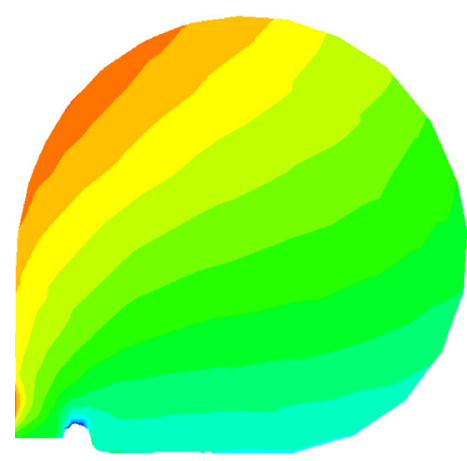

(a)

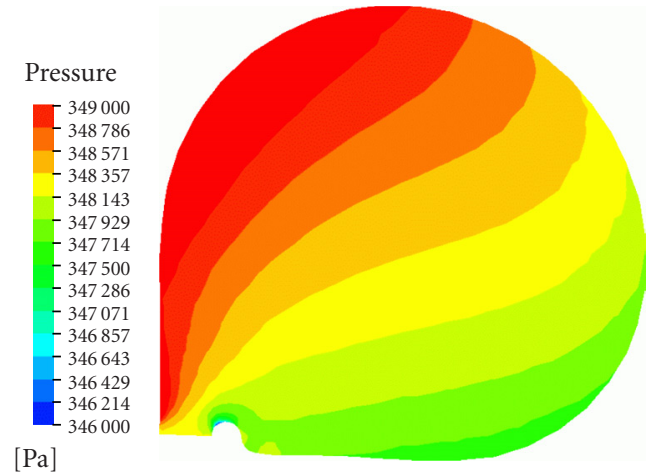

(b)

Figure 10: Static pressure contours at volute exit $\left(\theta=360^{\circ}\right)$, showing similar results as in Figure 9. (a) Sharp tongue. (b) Round tongue.

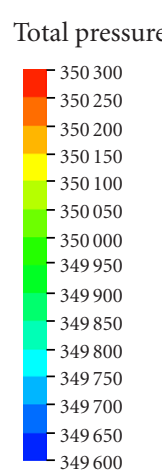

$[\mathrm{Pa}]$

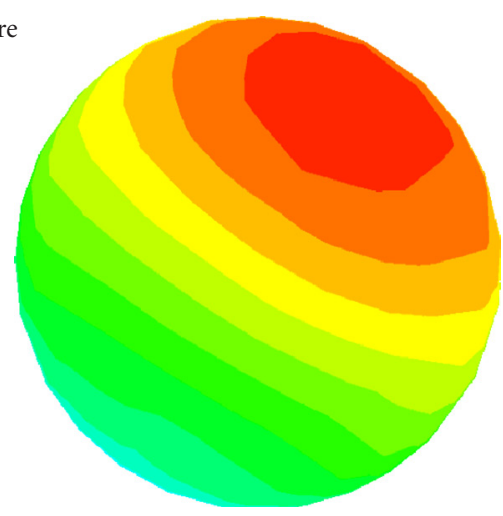

(a)

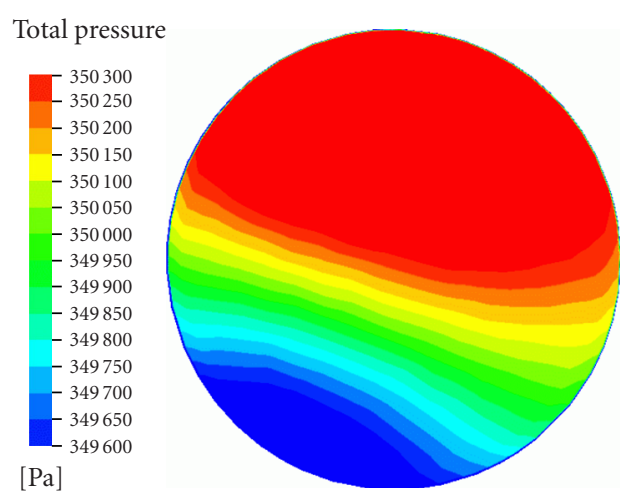

(b)

FIgURE 11: Total pressure contour at the discharge of exit cone. (a) Sharp tongue. (b) Round tongue, showing a much steeper pressure gradient, contributing to the secondary flow seen in Figure 7. 


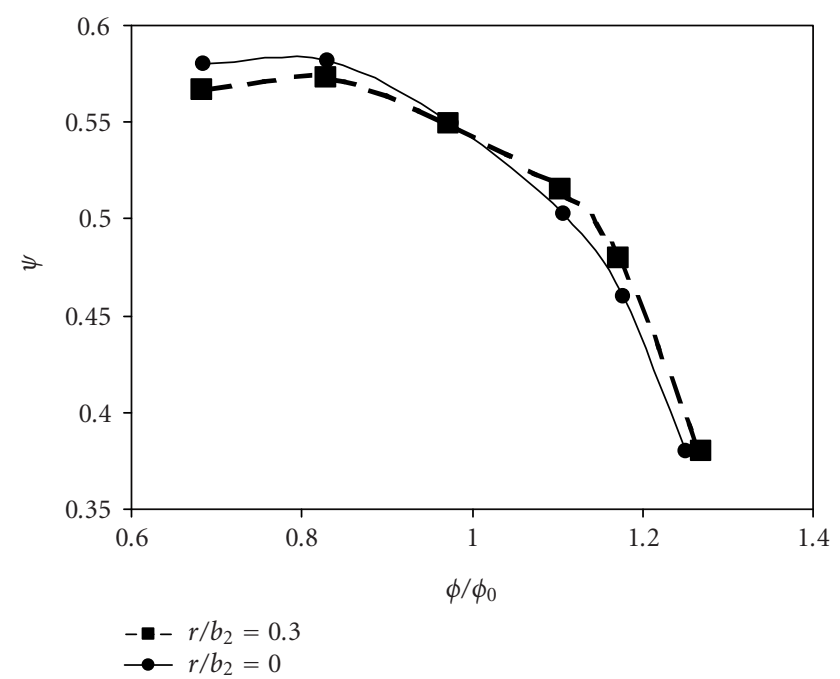

FIGURE 12: The performance characteristics of the two volute configurations discussed. The tradeoff between peak performance of the sharp tongue and the greater range of the round tongue is evident.

important that the round tongue is easier to cast, an important manufacturing consideration. This study sets a general guideline for centrifugal volute design.

\section{ACKNOWLEDGMENTS}

The authors would like to thank the Ingersoll-Rand Corporation, Air Solutions-Heavy Industrial Division-for allocation of resources, and the engineers in the Development Lab for their time and support in instrumentation and collection of experimental data.

\section{REFERENCES}

[1] E. Ayder, "Experimental and numerical analysis of the flow in centrifugal compressor and pump volutes," Ph.D. dissertation, Von Karman Institute for Fluid Dynamics, Rhode Saint Genese, Belgium, April 1993.

[2] E. Ayder and R. Van den Braembussche, "Numerical analysis of the three-dimensional swirling flow in centrifugal compressor volutes," Transactions of the ASME, Journal of Turbomachinery, vol. 116, no. 3, pp. 462-468, 1994.

[3] E. Ayder, R. Van den Braembussche, and J. J. Brasz, "Experimental and theoretical analysis of the flow in a centrifugal compressor volute," Transactions of the ASME, Journal of Turbomachinery, vol. 115, no. 3, pp. 582-589, 1993.

[4] F. Gu, A. Engeda, M. Cave, and J.-L. Di Liberti, "A numerical investigation on the volute/diffuser interaction due to the axial distortion at the impeller exit," Transactions of the ASME, Journal of Fluids Engineering, vol. 123, no. 3, pp. 475-483, 2001.

[5] S. Chu, R. Dong, and J. Katz, "Relationship between unsteady flow, pressure fluctuations and noise in a centrifugal pumppart B: effects of blade-tongue interactions," Transactions of the ASME, Journal of Fluids Engineering, vol. 117, pp. 30-35, September 1995.

[6] R. Dong, S. Chu, and J. Katz, "Effect of modification to tongue and impeller geometry on unsteady flow, pressure fluctua- tions and noise in a centrifugal pump," Transactions of the ASME, Journal of Turbomachinery, vol. 119, no. 3, pp. 506$515,1997$.

[7] K. Irabu, E. Tamazato, and I. Teruya, "Velocity measurement of flow around a volute tongue of the vaneless radial diffuser," in Proc. 3rd Asian Symposium on Visualization (ASV'94), Chiba, Japan, May 1994.

[8] ASME, Performance Test Code on Compressors and Exhausters, PTC10-1997, 1997.

[9] S. J. Kline, "The Purpose of uncertainty analysis," Transactions of the ASME, Journal of Fluids Engineering, vol. 107, pp. 153160, June 1985.

[10] C. Xu and R. S. Amano, "A hybrid numerical procedure for cascade flow analysis," Numerical Heat Transfer: Part B: Fundamentals, vol. 37, no. 2, pp. 141-164, 2000. 

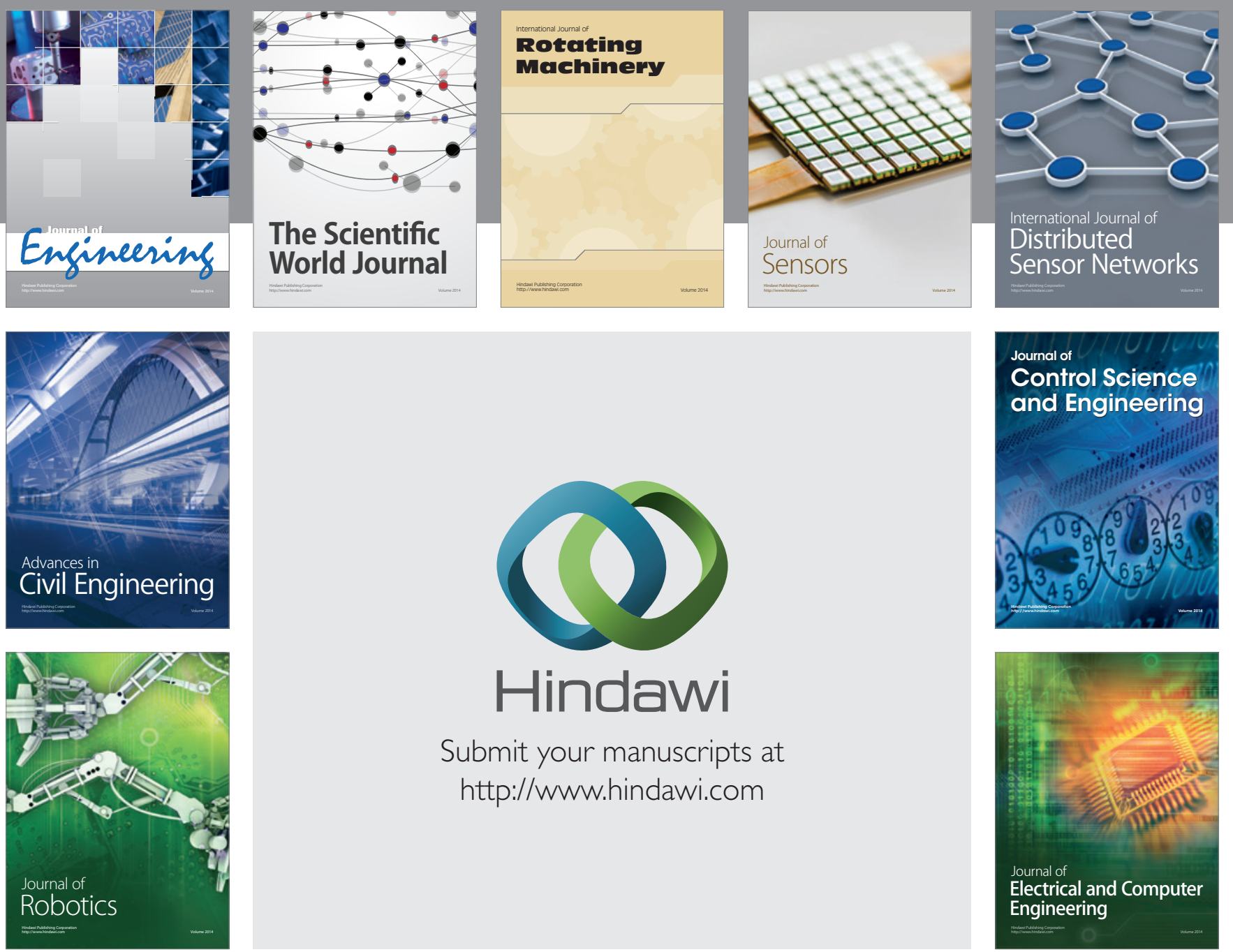

Submit your manuscripts at

http://www.hindawi.com
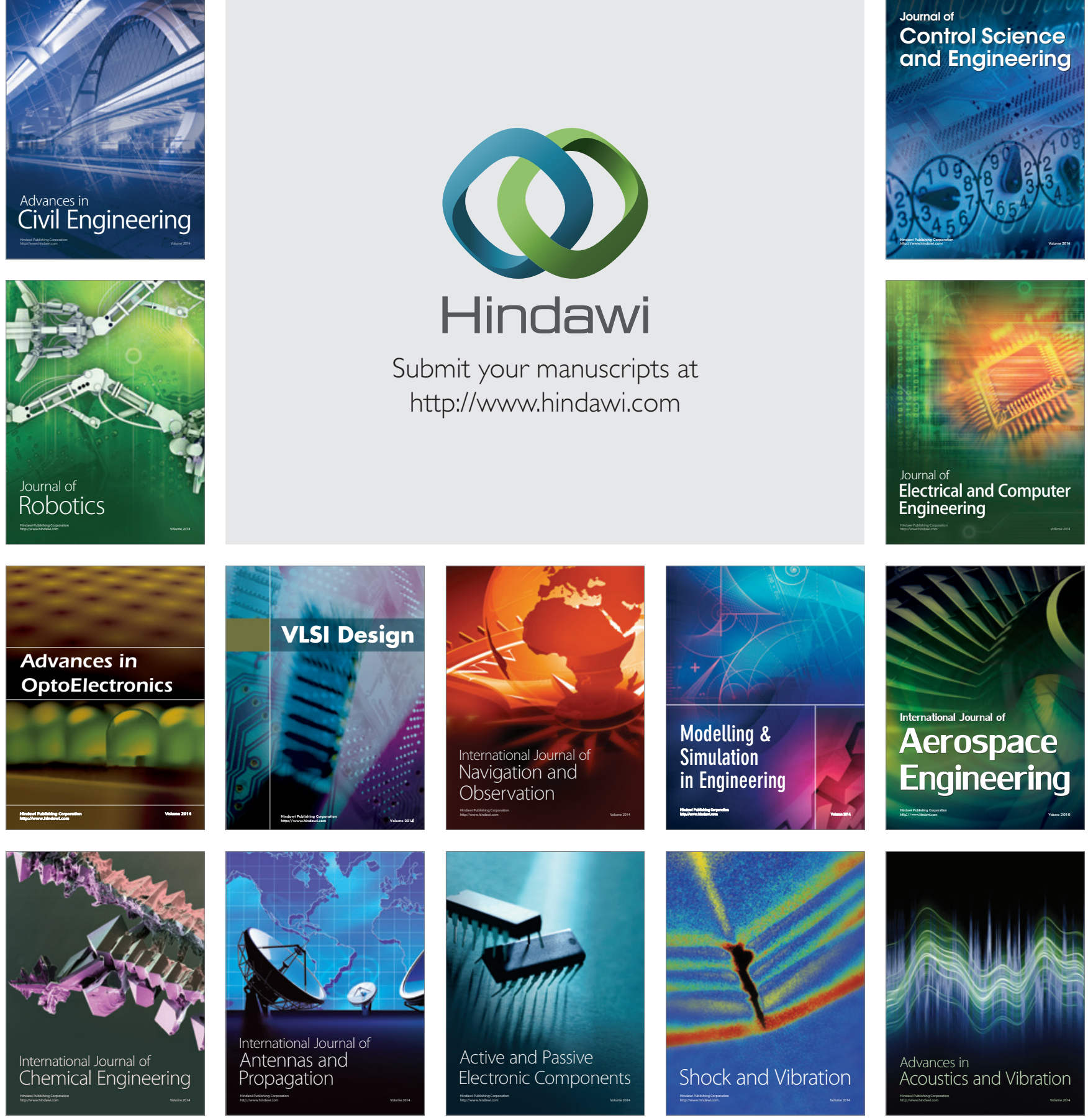